\title{
Breeding criteria and willingness to pay for improved Azawak zebu sires in Niger
}

\author{
S. Siddo ${ }^{1,2}$, N. Moula ${ }^{2,3}$, I. Hamadou ${ }^{1,2}$, M. Issa ${ }^{4}$, H. Marichatou ${ }^{4}$, P. Leroy ${ }^{2,3}$, and \\ N. Antoine-Moussiaux ${ }^{2,3}$ \\ ${ }^{1}$ Department of Animal Production, National Institute of Agronomic Research of Niger, P.O. Box 429, \\ Niamey, Niger \\ ${ }^{2}$ Fundamental and Applied Research for Animals \& Health (FARAH), Sustainable Animal Production, \\ Faculty of Veterinary Medicine, University of Liège, 4000 Liège, Belgium \\ ${ }^{3}$ Tropical Veterinary Institute, Faculty of Veterinary Medicine, University of Liège, Quartier Vallée 2, \\ Avenue de Cureghem 6, building B43, 4000 Liège, Belgium \\ ${ }^{4}$ Department of Animal Production, Faculty of Agronomy, University Abdou Moumouni, P.O. Box 10 960, \\ Niamey, Niger \\ Correspondence to: N. Antoine-Moussiaux (nantoine@ulg.ac.be)
}

Received: 26 April 2015 - Revised: 17 June 2015 - Accepted: 23 June 2015 - Published: 10 July 2015

\begin{abstract}
In Niger, the growth in local demand for milk and meat makes it necessary to consider genetic improvement of the indigenous cattle. At the Toukounous breeding station, the Azawak zebu has undergone over 50 years of line breeding for milk and meat production traits. To understand the adoption potential of improved Azawak sires in Niger, this study proposes to estimate the values that cattle keepers ascribe to different breeding criteria. In a first participatory stage, the breeding criteria used by cattle keepers were first listed and their relative importance was semi-quantified in three different production zones: pastoral, rural sedentary and peri-urban sedentary. The willingness to pay (WTP) for chosen breeding criteria have then been estimated through stated preference methods with 150 breeders. From participatory surveys, the most important attributes in sire choice were reproductive performance, feeding requirements and docility. The criteria considered for conjoint analysis (CA) were feeding requirements, docility, meat or dairy type, reproductive performance, coat color and tail length. The WTP was EUR 149 for low feed requirements, EUR 139 for docility and EUR 132 for a long tail. The meat and dairy type of the sire were less important in the decision-making.
\end{abstract}

\section{Introduction}

In Niger, the national demand for animal products has not been fulfilled and improvements of production modes are rapidly needed. To promote this change in family farming, the government has initiated a program for the genetic improvement of Azawak zebu sires resulting from a breeding program which has been ongoing since 1954 at the Toukounous experimental station (Marichatou et al., 2009). Encouraging the adoption of an improved breed calls for a thorough understanding of the willingness of livestock keepers to adopt this new technology. This willingness may be ideally expressed as willingness to pay (WTP), in order to estimate the potential market for genetic improvement, hence the opportunity for private investment or the need for public support. To understand this willingness, one should distinguish between the contributions of the different characteristics or attributes of a sire to its accepted price. The breeders' evaluation of these different attributes is needed to direct the genetic improvements, in agreement with consumer demand and the general improvement required by the adoption strategy, including communication, training and extension services. The variability of production systems is related to the variability of the appreciation of sires, for technical or sociocultural reasons. Thus, the adoption strategy might need to be adapted according to the production system in order to optimize it. 
Stemming from Lancaster's consumption theory (1971) and thus based on a multi-attribute approach, conjoint analysis (CA) considers that one good's utility derives from its different attributes, each attribute adopting different values or levels. From this postulate, CA allows for studying the behavior of consumers facing changes in the qualities of a product (i.e., a change in the levels of its attributes), generating estimations of utility coefficients for each level of each attribute (Drucker et al., 2001). Since the success of its first application in marketing in the 1970s, CA became a tool of scientific research (Silayoi and Speece, 2007). Hence, it has been used in diverse fields of study, including the management of genetic resources in different breeding systems, mainly in developing countries (Roosen et al., 2005). In recent applications, CA proved to be useful for evaluating the farmers' WTP for animal selection criteria (e.g., milk yield, disease resistance) or analyze the preferences of cattle buyers on the market (Markemann et al., 2010; Kassie et al., 2010, 2011). Indeed, in traditional husbandry systems, the appreciation of animals is based on production, functional and esthetic parameters (Röhler-Rollefson, 1997; Tano et al., 2003; Ouma et al., 2004; Kassie et al., 2011). Multifunctionality is a major characteristic of these systems (Ayalew et al., 2003), including the sociocultural value of animals and their attributes (Gandini and Villa, 2003; Ayantunde et al., 2007; Belli et al., 2008). Selection criteria are therefore not only based on productivity but also on the coat color, the faithfulness to the herder, the ability to walk long distances and to live in herds (Röhler-Rollefson, 1997). Many of these criteria do not have an observable monetary value in markets and the use of conventional tools for economic valuation do not allow for this valuation of genetic animal resources (Drucker et al., 2001). Stated preferences are therefore considered as a tool of choice for this task, generating values for the WTP of breeders for particular characteristics of different breeds (Roosen et al., 2005).

To the authors' knowledge, no such econometric study has been performed to estimate the value of animal genetic resources in Niger. This study proposes to apply these methods in the context of the adoption of elite Azawak zebu sires from Toukounous breeding station and the potential adjustment of this ongoing selective breeding program. It aims at studying the appreciation criteria of cattle keepers for Azawak zebu sires in the three main production systems of Niger (pastoral, rural sedentary and peri-urban sedentary) and at providing estimation of their WTP for selected attributes.

\section{Material and methods}

\subsection{Overall description of the study}

The study was conducted in three zones of Niger with different socioeconomic characteristics: a pastoral zone in Abalak, an agricultural zone in Filingué and a peri-urban zone in Niamey. In these three zones, a first survey mobilized participa- tory approaches (focus groups, visual scoring tools) to identify the breeders' main appreciation criteria for Azawak zebu sires. These results allowed for establishing a protocol for the conjoint analysis for the valuation of selected attributes of Azawak sires to be applied in the same three zones.

\subsection{Study area}

\subsubsection{Pastoral zone of Abalak}

The Abalak department is located in the Tahoua region. It has a semi-arid climate and a population density of 5.44 inhabitants per $\mathrm{km}^{2}$ (INS, 2010). Transhumant pastoralism is there the main activity. Commercial activities are limited to essential goods and livestock, within Niger or with neighboring countries (Nigeria, Benin, Libya and Algeria) (Pini and Tarchiani, 2007).

\subsubsection{Agricultural zone of Filingué}

Located in the northeast of the Tillabéri region, the Filingué department has a population density of 20.5 inhabitants per $\mathrm{km}^{2}$ (INS, 2010). Agriculture is there the main activity, often in mixed crop-livestock systems (Pini and Tarchiani, 2007). In the northern zone, crops only sustain households' livelihoods for 1 to 3 months vs. 8 to 10 months in the southern zone. Water infrastructure there is limited to traditional or cemented wells (Balla et al., 2007).

\subsubsection{Peri-urban zone of Niamey}

The urban commune of Niamey covers a surface area of $255 \mathrm{~km}^{2}$ with a population of 1.2 million (INS, 2010). Its climate is of the Sudano-Sahelian type. Animal husbandry is the second most common activity in the region, most often using semi-intensive systems (Gomma and Ruppol, 2000). Urbanization and agriculture have gradually encroached on former pastures, which are now limited to flood plains and peri-urban fallows (RGAC, 2007). The trade of crop residues for use as peri-urban livestock feed is now well developed (Gomma and Ruppol, 2000).

\subsection{Participatory survey on sire appreciation criteria}

\subsubsection{Sampling of focus groups}

The identification of appreciation criteria was undertaken in focus groups. In each of the three zones, cattle keepers were selected by snowball sampling on the basis of the first interviewees randomly selected from a list provided by local authorities. A diversity of interviewees was sought in terms of activity: cattle owners, professional herders, members or leaders of farmer associations (garso, rouga) and cattle traders (dillali).

With each focus group, an open discussion was first led on the appreciation criteria of Azawak zebu sires. The criteria were listed, written and represented by symbols on paper 
(for illiterate participants). A relative importance was then assigned to each criterion through proportional piling, using 100 counters. The consensus was sought through an iterative process and written notes were taken on the ongoing discussions. Each participant was asked for their opinion throughout the process. Motives for choices and disagreements were carefully investigated through open and probing questions.

\subsubsection{Statistical analyses}

Statistical analysis of participatory survey was conducted with R software (R 3.0.1). Differences of appreciation criteria between zones were tested through the Kruskal-Wallis test (function kruskal.test). The degree of agreement between groups, inside each zone and of the total sample, was analyzed by calculating Kendall's coefficient of concordance $(W)$ (package irr, function scoring). The contribution of each group to the overall concordance was obtained through Kendall's permutation test (package vegan, function kendall.global), with a correction for ex aequo scores (Legendre, 2005).

\subsection{Conjoint analysis of selection criteria}

\subsubsection{Identification of attributes, levels and the construction of sire profiles}

Six attributes with two to three levels each were retained to establish the stated preference protocol. The selection of attributes was made according to citation rate and proportional piling scores, as well as the main selection criteria applied at the Toukounous breeding station, i.e., milk production and growth. A price attribute was established on the basis of official statistics obtained from the Ministry of Livestock. Three levels were determined, i.e., XOF 170000 (EUR 259), XOF 145000 (EUR 221) and XOF 120000 (EUR 183), which represent respectively the third quartile, the median and the minimal price of the livestock trade records (young bulls) of February 2013 in the study zones (Système d'Information du Marché Bétail).

The combination of the different levels of these seven attributes allowed 288 potential sire profiles. A fractional design using the D-optimal algorithm (XLSTAT 2013) was used to randomly generate 16 sire profiles classified into twenty pairs of profiles (Tada et al., 2013). These profiles were illustrated by a local artist (Fig. 1).

\subsubsection{Stated preference survey: sampling and interviews}

In each of the three zones, 50 breeders were selected among the participants of the focus groups. The criterion to be included was to own Azawak zebu and to be in charge of decision-making regarding breeding. In each face-to-face interview, the twenty pairs of profiles were proposed to the breeder, and they were asked which animal they would buy.

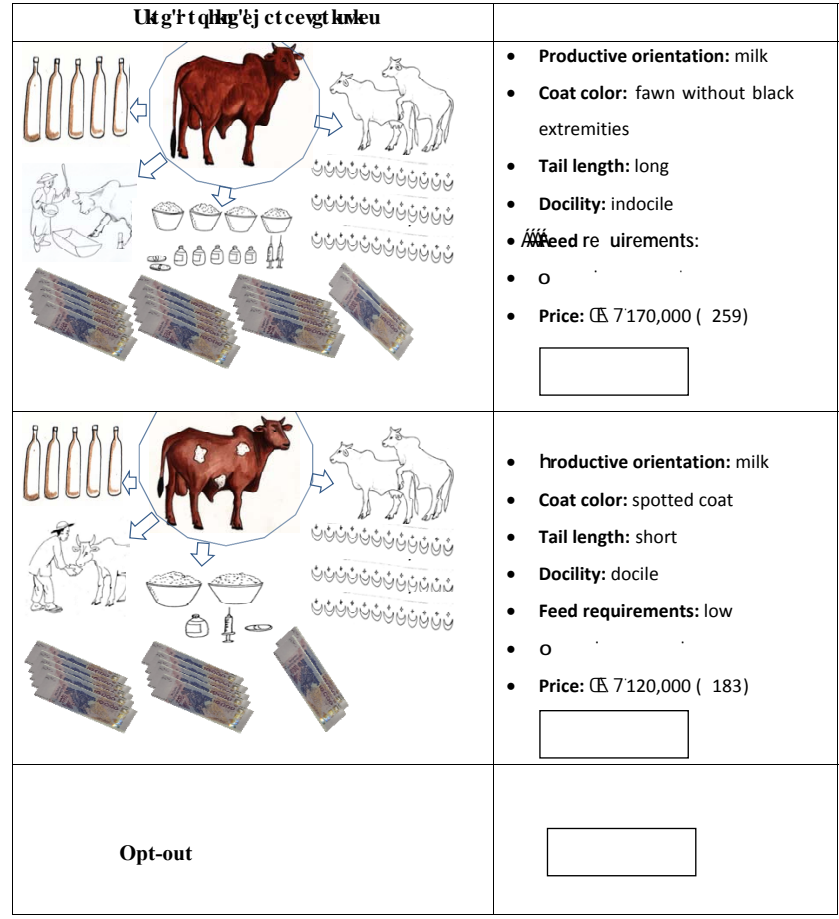

Figure 1. Example of pair-wise comparison choice card.

The interviewee had for each pair the possibility to opt out, i.e., to state that none of the two profiles were acceptable. After the twenty choices, short open discussions examined the interviewees' perception of the method as well as the motives of their choices and the strategy they tended to adopt to make these choices. Written notes of this qualitative information were taken during the interview.

\subsubsection{Statistical analysis and estimation of the WTP}

Econometric analysis of stated preferences was performed with R software (R3.0.1, package survival, package support.Ces). The estimation of utility coefficients used the conditional logit model: $P_{i, j}=\exp \left(V_{i}\right) / \Sigma \exp \left(V_{j}\right)$, where $P_{i, j}$ is the probability for object $i$ to be preferred among $j$ objects, expressed as a logit function of the object utility $V_{j}$ $(i \in j)$. The utility $V_{j}$ was modeled as a linear function of the levels of each attribute of the object $j$, i.e., by the formula $V_{j}=\beta_{0}+\Sigma \beta_{k l} X_{k}+\varepsilon_{j}$, where $\beta_{0}$ is a constant, $\beta_{k l}$ the utility coefficient of level $l$ of the attribute $X_{k}$ for the object $j$ and $\varepsilon_{j}$ a random error term. For the total panel, the model estimates a utility coefficient for each level of each attribute $\left(\beta_{k l}\right)$ given the general structure of interviewees' choices. The price variable was expressed in euros for statistical analysis.

The WTP corresponds to a monetary conversion of utility coefficients of each attribute's level, according to the method described by Tada et al. (2013). The WTP for a level $l$ of an attribute $k$ is calculated as follows: $\mathrm{WTP}_{k l}=-\beta_{k l} / \beta_{€}$, with 
Table 1. Appreciation criteria for Azawak zebu sires in three production zones of Niger, citation in focus group discussions and proportional piling scores. Ns stands for not significant.

\begin{tabular}{|c|c|c|c|c|c|c|c|c|c|c|c|c|c|}
\hline \multirow{2}{*}{$\begin{array}{l}\text { Appreciation } \\
\text { criteria }\end{array}$} & \multicolumn{3}{|c|}{ Agricultural zone $N=14$} & \multicolumn{3}{|c|}{ Pastoral zone $N=15$} & \multicolumn{3}{|c|}{ Urban zone $N=15$} & \multicolumn{3}{|c|}{ Total sample $N=44$} & \multirow{2}{*}{$\begin{array}{r}\text { Stat. diff. } \\
\text { between zones }\end{array}$} \\
\hline & Citation* \% & Median & Range & Citation \% & Median & Range & Citation \% & Median & Range & Citation $\%$ & Median & Range & \\
\hline Fawn-colored coat & 57.14 & 16.5 & $6-29$ & 93.33 & 21.5 & $6-42$ & 80.00 & 18.0 & $4-45$ & 77.27 & 12.5 & $4-45$ & $\mathrm{Ns}$ \\
\hline Long tail & 78.57 & 21.0 & $10-32$ & 86.67 & 18.0 & $7-36$ & 53.33 & 16.5 & $11-26$ & 72.73 & 18.5 & $7-36$ & $\mathrm{Ns}$ \\
\hline Docile & 100.00 & 17.5 & $3-53$ & 40.00 & 7.0 & $2-16$ & 73.33 & 16.0 & $4-38$ & 70.45 & 20.0 & $2-53$ & $p<0.001$ \\
\hline Good body shape & 71.43 & 22.5 & $15-35$ & 66.67 & 16.5 & $8-31$ & 66.67 & 24 & $5-36$ & 68.18 & 21.5 & $5-36$ & $\mathrm{Ns}$ \\
\hline $\begin{array}{l}\text { Milk production of } \\
\text { half-sisters }\end{array}$ & 35.71 & 14.0 & $10-19$ & 73.33 & 17.0 & $7-25$ & 80.00 & 16.0 & $4-39$ & 63.64 & 15.5 & $4-39$ & $p<0.05$ \\
\hline Testicles (big, equal) & 64.29 & 17.0 & $6-30$ & 60.00 & 17.0 & $6-25$ & 33.33 & 19.0 & $12-26$ & 52.27 & 17.0 & $6-30$ & $\mathrm{Ns}$ \\
\hline $\begin{array}{l}\text { Milk production of } \\
\text { mother }\end{array}$ & 35.71 & 9.0 & $5-23$ & 60.00 & 10.0 & $3-21$ & 33.33 & 21.0 & $5-30$ & 43.18 & 9.0 & $3-30$ & $\mathrm{Ns}$ \\
\hline Firm hump & 21.43 & 10.0 & $8-13$ & 53.33 & 14.0 & $3-22$ & 26.67 & 15.0 & $5-21$ & 34.09 & 13.0 & $3-22$ & $\mathrm{Ns}$ \\
\hline Size (tall) & 14.29 & 20.0 & $16-24$ & 26.67 & 16.0 & $14-29$ & 26.67 & 10.0 & $1-24$ & 22.73 & 15.0 & $1-29$ & $\mathrm{Ns}$ \\
\hline Short horns & 50.00 & 12.0 & $6-20$ & 6.67 & 4.0 & 4-4 & 6.67 & 5.0 & $5-5$ & 20.45 & 7.0 & $4-20$ & $p<0.01$ \\
\hline Good stance & 28.57 & 11.0 & $10-22$ & - & - & - & 26.67 & 18.0 & $10-25$ & 18.18 & 14.5 & $10-25$ & Ns \\
\hline Big head & 14.29 & 4.5 & $3-6$ & 13.33 & 13.5 & $9-18$ & 6.67 & 13.0 & $13-13$ & 11.36 & 9.0 & $3-18$ & $\mathrm{Ns}$ \\
\hline Wide chest & 7.14 & 8.0 & $8-8$ & 6.67 & 16.5 & $9-24$ & 13.33 & 15.0 & $10-20$ & 11.36 & 10.0 & $8-24$ & $\mathrm{Ns}$ \\
\hline $\begin{array}{l}\text { Black-colored spot } \\
\text { around eyes }\end{array}$ & - & - & - & 26.67 & 11.5 & $5-27$ & 6.67 & 17.0 & $17-17$ & 11.36 & 15.0 & $5-27$ & $\mathrm{Ns}$ \\
\hline Strong neck & 7.14 & 15.0 & $15-15$ & 6.67 & 5.0 & $5-5$ & 13.33 & 11.5 & $10-13$ & 9.09 & 11.5 & $5-15$ & $\mathrm{Ns}$ \\
\hline Dominant behavior & - & - & - & - & - & - & 6.67 & 19.0 & $19-19$ & 2.27 & 19.0 & $19-19$ & Ns \\
\hline
\end{tabular}

* Percentage of focus groups citing the criterion.

$\beta_{k l}$ as defined earlier and $\beta_{€}$ being the utility coefficient of the monetary unit (EUR).

In order to analyze the effect of price on the choice, the price variable was considered as categorical in a second analysis using the same model.

The relative importance of an attribute $k$ was calculated as $\mathrm{RI}_{k}=100 \times\left(\beta_{k l_{-} \max }-\beta_{k l_{-} \min }\right) / \Sigma\left(\beta_{k l_{-} \max }-\beta_{k l_{-} \min }\right)$, where $\beta_{k l \_m a x}$ and $\beta_{k l} l_{\text {min }}$ are respectively the maximal and minimal utility coefficient among the levels $l$ of an attribute $k$.

\section{Results}

\subsection{Appreciation criteria for Azawak sires}

A total of 44 focus groups discussions were held (14 in the agricultural zone, 15 in the peri-urban zone, 15 in the pastoral zone), gathering 288 cattle owners (median group size of 7 people, range: $4-8$ ), of which $14.0 \%$ were women and $86.0 \%$ were men. Sixteen appreciation criteria for Azawak sires were identified, belonging to three categories: morphological, productive and behavioral. The criteria and their scores are presented for each zone in Table 1.

Among morphological attributes, the major criterion was the coat color, cited by $77.3 \%$ of focus groups with a median score of $18.0 \%$ (range: 4-45). Body format was cited by $68.2 \%$ of groups with a median score of $21.5 \%$ (range: 5-36). The attribute docility, cited by $70.5 \%$ of groups, obtained a median score of 16 (range: 2-53). The dairy production of the progeny of the father of the sire (half sibling of the sire) was cited by $63.6 \%$ of focus groups with a median score of 15.5 (range: 4-39). The dairy production of the mother of the sire was cited by $43.2 \%$ of focus groups.
Most of proportional piling scores did not show any statistical differences between zones $(p>0.05)$ (Table 1). Three criteria showed a statistically different importance between zones. Docility was less valued in the pastoral zone (citation rate $40.0 \%$, median 7 , range: $2-16$ ) in comparison with the agricultural zone (citation rate $100.0 \%$, median 17.5, range: $3-53$ ) and the peri-urban zone (citation rate $73.3 \%$, median 16 , range: $4-38)(p<0.001)$. Short horns were more appreciated in the agricultural zone (citation rate $50.0 \%$, median 12, range: 6-20) and less so in the pastoral and peri-urban zones, where they were cited by only one focus group (with scores of 4 and 5 , respectively) $(p<0.01)$. The dairy production of the half-sisters of the sire was slightly less well appreciated in the agricultural zone (citation rate $35.7 \%$, median 14, range: 10-19) in comparison with the pastoral zone (citation rate $73.3 \%$, median 17 , range: $7-25)$ and the peri-urban zone (citation rate $80.0 \%$, median 16 , range: $4-39)(p<0.5)$.

Kendall's coefficient of concordance $(W)$ in the three zones showed medium and highly significant values $(p<0.001)$, i.e., 0.47 in the agricultural zone, 0.50 in the pastoral zone, and 0.50 in the peri-urban zone. Inside zones, the concordance coefficients of each group with the others were between 0.35 and $0.63(p<0.05)$.

\subsection{Sample characteristics of the stated preference survey}

The socioeconomic characteristics of surveyed breeders are presented in Table 2. Among the 150 participants, $80.0 \%$ were men and $20.0 \%$ women. The median age was 45 years (range: 21-76). Breeders below 35 years old constituted $12.6 \%$ of the sample. $45.3 \%$ of participants were illiterate; $54.7 \%$ were able to read and write in French or Arabic. Their 
Table 2. Socioeconomic characteristics of surveyed Azawak breeders $(n=150)$.

\begin{tabular}{|c|c|c|c|}
\hline & & Frequency & $\%$ \\
\hline \multirow[t]{5}{*}{ Age } & $<35$ years & 19 & 12.67 \\
\hline & 35 to 40 & 26 & 17.33 \\
\hline & 41 to 46 & 34 & 22.67 \\
\hline & 47 to 53 & 26 & 17.33 \\
\hline & $<53$ & 45 & 30.00 \\
\hline \multirow[t]{4}{*}{ Household size } & $<6$ persons & 23 & 15.33 \\
\hline & 6 to 10 & 69 & 46.00 \\
\hline & 11 to 15 & 38 & 25.33 \\
\hline & $>15$ & 20 & 13.33 \\
\hline \multirow[t]{5}{*}{ Cattle herd size } & $<7$ & 25 & 16.67 \\
\hline & 7 to 14 & 40 & 26.67 \\
\hline & 15 to 21 & 35 & 23.33 \\
\hline & 22 to 28 & 21 & 14.00 \\
\hline & $>28$ & 29 & 19.33 \\
\hline \multirow[t]{2}{*}{ Gender } & Female & 30 & 20.00 \\
\hline & Male & 120 & 80.00 \\
\hline \multirow[t]{3}{*}{ Education } & Arabic & 46 & 30.67 \\
\hline & French & 36 & 24.00 \\
\hline & Illiterate & 68 & 45.33 \\
\hline \multirow[t]{3}{*}{ Main activity } & Agriculture & 53 & 35.33 \\
\hline & Trade & 16 & 10.67 \\
\hline & Livestock & 81 & 54.00 \\
\hline \multirow[t]{5}{*}{ Ethnic group } & Arab & 6 & 4.00 \\
\hline & Hausa & 41 & 27.33 \\
\hline & Fulani & 30 & 20.00 \\
\hline & Tuareg & 67 & 44.67 \\
\hline & Zarma & 6 & 4.00 \\
\hline
\end{tabular}

main activity was livestock (54.0\%), agriculture (35.3\%) or trade $(10.7 \%)$. The distribution of main activities was significantly different between zones $(p<0.01)$. In the pastoral zone, livestock $(86.0 \%)$ dominated agriculture $(8.0 \%)$ and trade $(6.0 \%)$.The distributions in the agricultural and periurban zones were similar, with a greater importance of agriculture as the main activity (52.0 and $46.0 \%$, respectively), followed by livestock (38.0\% in both zones) and trade (10.0 and $16.0 \%$, respectively).

The median size of cattle herds was 16 heads (range: $2-$ 119 ), with about $80.6 \%$ of herds below 28 heads. The median household size was 9 active persons (range: 2-30). $13.3 \%$ of interviewed breeders were living in households including over 15 persons. Five ethnic groups composed the sample, mainly Tuareg (44.7\%), Hausa (27.3\%) and Fulani (20.0\%).

\subsection{Conjoint analysis and WTP calculation}

From the participatory survey, the following attributes (and levels) were integrated for the stated preference survey: coat color (fawn with black extremities, fawn without black extremities, spotted coat), productive orientation (milk, meat), tail length (long, short), feed requirements (high, low), docility (docile, indocile), and sexual precocity (early: 2 years, late: 3 years).

The utility coefficients and WTP estimated for each level of each attribute are presented in Table 3. For each attribute, one level is defined as a reference with a null coefficient and other levels' coefficients represent the utility gained when changing from the reference level to the level considered. The utility coefficients of the other levels were positive and highly significant statistically $(p<0.001)$, indicating their appreciation by respondents.

The utility coefficient of the monetary unit was $-0.004(\mathrm{SE}=0.001)$, i.e., negative and highly significant $(p<0.001)$, indicating the general disutility attached to expense. When analyzed as a categorical variable, the intermediate price level (EUR 221) obtained a utility coefficient $-0.164(\mathrm{SE}=0.09 ; p=0.071)$ and the highest price (EUR 259) a utility coefficient of $-0.361(\mathrm{SE}=0.106$; $p<0.001)$.

The highest utilities and thus the highest WTP were attached to the levels "low feed requirements" (EUR 149), "docile" (EUR 139) and "long tail" (EUR 132). Accordingly, the attributes feed requirement, docility and tail length showed the highest relative importance with 21.3, 19.9 and $18.9 \%$ respectively. Sexual precocity obtained a WTP of EUR 113, with a relative importance of the attribute of $16.1 \%$. The productive orientation and coat color were less important in the participants' choice, with relative importance of 12.3 and $11.6 \%$, respectively. The "dairy orientation" and "fawn-colored coat" (with black extremities) were the preferred levels of these attributes, obtaining similar WTP, at EUR 82 and EUR 87, respectively.

\section{Discussion}

\subsection{Participatory survey on appreciation criteria}

The concordance between focus groups about the relative importance of the different appreciation criteria for Azawak sires was medium and similar between zones. Although this study did not focus on production practices, the differences between zones could be illustrated through the different proportions of people raising livestock as their main activity. Differences in the appreciation of Azawak zebu sires between zones proved to be quite limited. The coat color, the length of the tail and the body format were the criteria the most commonly and strongly valued. Nevertheless, some differences proved statistically significant in the appreciation of docility, horns size and the milk production of the sires' halfsisters. Docility was less appreciated in the pastoral zone than in the peri-urban and agricultural zones while short horns were more valued in the agricultural zone. These two differences may be understood as due to the use of zebu as a 
Table 3. Utility coefficients and willingness to pay estimated for Azawak sire traits in Niger.

\begin{tabular}{llrrr}
\hline Attributes & Levels & Marginal utility & MWTP (EUR) & CI 95 \% (EUR) \\
\hline Coat color & Fawn with black extremities & $0.31 \pm 0.08^{* * *}$ & 82 & $39-187$ \\
& Fawn without black extremities & $0.28 \pm 0.08^{* * *}$ & 0 & $26-192$ \\
& Spotted coat & $0.33 \pm 0.06^{* * *}$ & 0 & 0 \\
\hline Productive orientation & Milk & 0 & 87 & $47-204$ \\
& Meat & 0 & 0 \\
\hline Tail length & Short & $0.50 \pm 0.06^{* * *}$ & 0 & 0 \\
& Long & $0.57 \pm 0.06^{* * *}$ & 132 & $79-296$ \\
\hline Feed requirements & Low & 0 & 149 & $91-331$ \\
& High & $0.53 \pm 0.06^{* * *}$ & 0 & 0 \\
\hline Docility & Docile & 0 & 139 & $85-304$ \\
& Indocile & & 0 & 0 \\
\hline Sexual precocity & Late (3 years) & $0.43 \pm 0.05^{* * *}$ & 0 & 0 \\
& Early (2 years) & $-0.004 \pm 0.001^{* * *}$ & 113 & $68-243$ \\
\hline Price & & & - & - \\
\hline
\end{tabular}

MWTP: mean willingness to pay; CI: confidence interval; significance codes: ${ }^{* * *}=p \leq 0.001$.

draught animal in the agricultural zone, hence the need for animals that are docile and with less dangerous horns. In the pastoral zone, less docile animals and longer horns may be considered as an advantage for the ability of the animals to defend themselves against theft. The difference in the appreciation of the milk production of the sires' half-sisters might refer to a difference in the dairy orientation of the herds, which is more fundamental to the present work. Nevertheless, although statistically significant, this difference is moderate and the similar appreciation of the milk production ability of the sires' mother rather indicates that the difference lies in the source of information considered rather than in the importance of milk production itself.

The absence of major differences between the three study zones justified considering the three zones as a single unit in the choice experiment, without the goal of comparative analysis. As a result, the study intentionally focused on the possibility for one single strategy to be adopted in the three zones for the continuation of genetic progress in the Toukounous station and the adoption of improved Azawak sires.

\subsection{Conjoint analysis}

\subsubsection{The price}

In a conjoint analysis, the price attribute plays the role of the monetary counterpart of the other attributes. Hence, the decision-making appears as a trade-off between the disutility of spending money and the utility of the animal's attributes, of which the accepted price (WTP) is then derived. In this study, the analysis of the price attribute as a categorical variable allowed observing that a statistically significant disutil- ity was attached to the highest price compared to the lowest. The intermediate price only presented a statistical trend to disutility $(p=0.071)$. From the short open interviews held after the choice experiments, we suggest that the degree of disutility tied to expense might be underestimated due to the interpretation of price itself as an indicator of animal's quality. This type of interpretation of price is a widespread psychological feature in buying decisions, which is exploited in marketing (Kirmani and Rao, 2000). In the present case, this interpretation constitutes a limit of the method, affecting the overall estimation of other attributes' WTP. In order to prevent this psychological effect, we propose explicitly addressing the fact that the price is not considered a sign of quality with each interviewee.

\subsubsection{Productive and reproductive attributes}

Production performance, which is classically valued in modern breeding programs, does not appear as one of the most appreciated attributes in the present survey. The production orientation attribute showed, indeed, a low relative importance in the decision-making of participants, with a preference for dairy orientation of the sire. Regarding reproduction, sexual precocity nevertheless obtained a high WTP, justified in open interviews by the willingness to rapidly increase the herd size. These observations are in agreement with the financial role of the herd in these households, i.e., a role of savings in which income generation occurs sporadically to satisfy major financial needs of the household, then mainly through the sale of young males without a fattening stage (Kassie et al., 2011). Moreover, in African pastoral communities, herd size is also considered as a sign of 
social status, being an indicator of the household's wealth (Cantoni and Lallau, 2010). In Kenya, Ouma et al. (2004) reported a similar preference for reproduction performance compared to milk production. Likewise, in Burkina Faso, Tano et al. (2003) observed that the appreciation of cows and bulls was firstly based on the vigor of their calves, rather than on milk or meat production attributes.

Despite the lower overall importance of the production attribute, the fact that dairy orientation was preferred to meat orientation illustrates the importance of milk for households' livelihoods. Actually, this importance might be underestimated by the present study due to the lower presence of women in the sample (focus group interviews and conjoint analysis). Indeed, milk appeared in these discussions as a domestically consumed good, with very low financial interest for the male members of households who dominated the sample. This potential gender bias deserves further investigation through distinct interviews in men and women. Traditionally, in Hausa, Fulani and Zarma households, women own the milk, which is mainly used for consumption at home. In Arab or Tuareg households, the milk may rather be considered as a wage for the herder, also for consumption. This, again, is similar to what is described in Burkina Faso (Tano et al., 2003) and Ethiopia (Kassie et al., 2011), where the sale of milk is not culturally accepted.

The present study adopted a sampling strategy taking account of the decision power of the interviewee in their household regarding the purchase of sires. As such, the dominance of male interviewees in the present sample directly results from that choice, expressing the dominance of men in this purchase decision. Therefore, the practical market described here might substantially differ from more general interest, in which milk production would take greater importance. In terms of the adoption strategy, the public goal of animal protein production would thus be constrained by the low priority of these production attributes in the buyer's decision-making.

Peri-urban animal husbandry in Niger (as in many countries of Africa) would be expected to follow a different scheme compared to rural production, with increased interest in milk marketing directly to city dwellers or to dairy industry (Vias et al., 2003; Vias and Banzhaf, 2008; Boukary et al., 2007; Hamadou et al., 2008). This peri-urban production appears as more specialized, investing in housing, feed, health and making use of exotic breeds (Alary et al., 2007). Indeed, in the peri-urban zone of Niger, this sector is home for crossbreeds between indigenous breeds (Azawak, Djelli, Gudali) and exotic ones (Piémontais, Holstein, Brown Swiss, Valdotaine) (Marichatou et al., 2009). In southeast Kenya, Ouma et al. (2004) also showed how the importance of milk among the appreciation criteria of cattle differs between husbandry systems and objectives. For these reasons, strong demand would be expected in the peri-urban settings for improved Azawak sires that exhibit better milk production performance. The present results are however not in agreement with this expectation. This might be explained by the sam- pling strategy that intentionally included purebred Azawak zebu owners, therefore excluding crossbred owners who are more production-oriented. This purposive sampling was justified in this study because of the objective to characterize the demand for Azawak zebu sires, while peri-urban crossbred owners, to increase their milk production consider exotic breeds instead. This preferred use of exotic breeds for potential improvement of milk production might also be true for purebred Azawak owners, thus explaining that they did not look for this particular quality when considering the purchase of an Azawak sire.

\subsubsection{Functional attributes}

The most appreciated attribute was the low feed requirements, obtaining a WTP of EUR 149, corresponding to around $57 \%$ of the highest price considered. This may be interpreted as a lack of willingness or a lack of ability of the animal keepers to increase the use of inputs in the short or even the medium term. This point was made explicit during open discussion as breeders stated the need for the feeding system to remain based on the exploitation of common pastures. This cost-minimization strategy has to be understood in the context of the above-described savings role of cattle, without a specialized animal production goal. Indeed, feeding and veterinary care represent the most important share of the cash spent in animal husbandry in such family farming (Tano et al., 2003; Ouma et al., 2004; Mwacharo et al., 2005; Zander and Drucker, 2008). The present study thus confirms that the lack of physical and financial access to input supply is a major constraint to the adoption of improved sires, which are also more input demanding.

This constraint appears here as internalized in the decision-making process as the most important choice criterion, sometimes expressed by breeders as the need for the animal to fit the context. These results are similar to those of Makokha et al. (2007) in semi-intensive dairy farms of Kenya, where they noted the preference of farmers for cows with low feed requirements. Tano et al. (2003) also showed in Burkina Faso that the breeders depreciate animals with a selective feeding behavior at pasture. In that study, disease resistance and the low feed requirements were also more important in cattle's appreciation than milk production (Tano et al., 2003).

The focus group discussions in the first stage of the study show that the docility was a widely shared appreciation criterion $(70.4 \%)$, which was then confirmed through CA as the second most important criterion (WTP EUR 139). This importance was justified by the use of the sire for draught and fattening purposes. According to interviewees' further justifications, the labor for these tasks is mainly undertaken by children and women, hence resulting in the particular attention paid to docility. In their participatory study on selection criteria for Ankole cattle in Uganda, Kugonza et al. (2012) 
reported the reverse expression of the same choice, i.e., the use of indocility as a major criterion for culling.

\subsubsection{Morphological and esthetic attributes}

In both traditional and modern breeding schemes, esthetic attributes of animals remain important, including the color of the coat. That criterion proved here a widely shared criterion in the participatory stage of the study and was then shown to be as important as the milk production attribute through conjoint analysis. The preference was then given to fawn-colored coats with black extremities (WTP of EUR 82 compared to the spotted coat). This coat is indeed considered traditionally as the standard coat of the Azawak zebu and is the standard used for 30 years in the Toukounous breeding station. In the owners' opinion, this coat color gets higher prices on markets, justified by its cultural significance and related to the color of the ground of the Azawak Valley (a recurrent explanation brought up in focus group discussions). Therefore, this orientation of Toukounous' breeding scheme appears in accordance with demand and might be better exploited in adoption messages. Such importance of coat color as a selection criterion is very common in traditional breeding systems (Tano et al., 2003; Ouma et al., 2004; Wurzinger et al., 2006; Zander and Drucker, 2008; Kugonza et al., 2012), resulting in higher prices for the cattle showing the appreciated color coat, as for example the black coat that is highly valued on Ethiopian markets (Kassie et al., 2011). The justification of this importance through the argument of tradition is also found elsewhere (Ouma et al., 2004; Ndumu et al., 2008). More precisely, the coat color may draw its importance from ceremonies in which religious and traditional rule must be respected (Ouma et al., 2004).

The length of the tail appeared as even more valued than coat color. From individual interviews and focus groups discussions, it appeared that breeders associate this criterion with breed purity. The link with good milk production was also suggested by several breeders. Kugonza et al. (2012) reported similar considerations about the link between a long tail and good milk production, according to Ankole cattle owners in Uganda. That study also reported the link made by breeders between milk production and the size of testicles. The criterion of the size of the testicles was also mentioned by owners in the present study, but was rather justified through better reproductive performance.

\section{Conclusions}

This study allowed estimating with standard econometric methods the market value of selection attributes of Azawak zebu cattle in Niger in the prospect of designing a suitable adoption strategy for improved sires from the Toukounous breeding station. Increased milk production or weight gain, which would improve the livelihoods of cattle-owning households, did not appear as major decision criteria in this study. Identified as a national priority, this objective will be maintained for both selection and adoption, but its neglect in the cattle owners' buying decision needs to be understood to adapt the adoption message. It has been proposed that the poor access to inputs is a major constraint in this regard, and is internalized in the breeders' decision-making in family farming systems where multi-functionality, and technical and financial constraints prevail. In the medium term, good access to inputs and a rapid specialization of farms may not be expected to contribute to the national objective of inclusive growth. In this regard, access to inputs and veterinary services will remain a priority to achieve this goal in the near future. However, understanding the appreciation criteria should help increase the adoption of superior Azawak sires among smallholders and help gradually build sustainable improved systems, based on an indigenous genetic resource.

Edited by: A.-E. Freifrau von Tiele-Winckler

Reviewed by: A. V. Zárate and one anonymous referee

\section{References}

Alary, V., Chalimbaud, J., and Faye, B.: Multiple determinants of milk production in Africa; the exemple of the diversity of dairy farming systems in the Mbarara area (Uganda), Afr. Dev., 32, 156-180, 2007.

Ayalew, W., Rischkowsky, B., King, J. M., and Bruns, E.: Crossbreds did not genereate more net benefits than indigenous goats in Ethiopian smallholdings, Agric. Syst., 76, 1137-1156, 2003.

Ayantunde, A. A., Kango, M., Hiernaux, P., Udo, H. M. J., and Tabo, R.: Herders' perceptions on ruminant livestock breeds and breeding management in Southwestern Niger, Hum. Ecol., 35, 139-149, 2007.

Balla, A., Yamba, B., Adam, T., and Abdou, D.: Etat des lieux sur la vulnérabilité des ménages au niveau local. Université Abdou Moumouni de Niamey, Projet d'Appui au dispositif National de Prévention et de gestion des Crises Alimentaires au Niger(APCAN), 61 pp., 2007.

Belli, P., Turni, J., Harouna, A., Garba, I. A., Pistocchini, E., and Zecchini, M.: Critères de sélection des bovins laitiers par les éleveurs autour de Niamey au Niger [Farmers' selection criteria for dairy cattle in and around Niamey in Niger], Rev. Elev. Méd. Vét. Pays trop., 61, 51-56, 2008.

Boukary, A. R., Chaibou, M., Marichatou, H., and Vias, G.: Caractérisation des systèmes de production laitière et analyse des stratégies de valorisation du lait en milieu rural et périurbain au Niger : cas de la communauté urbaine de Niamey et de la commune rurale de Filingué [Characterization of Dairy Production Systems and Analysis of Milk Promotion Strategies in Rural and Urban Areas in Niger: Case of the Urban Community of Niamey and Rural District of Filingue], Rev. Elev. Med. Vét. Pays trop., 60, 113-120, 2007.

Cantoni, C. and Lallau B.: La résilience des Turkana, Développement durable et territoires, 1, 1-19, doi:10.4000/developpementdurable.8497, 2010. 
Drucker, A. G., Gomez, V., and Anderson, S.: The economic valuation of farm animal genetic resources: a survey of available methods, Ecol. Econ., 36, 1-18, 2001.

Gandini, G. and Villa, E.: Analysis of the cultural value of local livestock breeds: a methodology, J. Anim. Breed. Genet., 120, $1-11,2003$.

Gomma, A. D. and Ruppol, P.: Etude sur la production des ruminants en milieu urbain et périurbain de Niamey, Niger. Université de Liège et Vétérinaires Sans Frontières/Belgique, 72 pp., 2000.

Hamadou, S., Tou, Z., and Toé, P.: Milk, an expanding diversification product in periurban Bobo-Dioulasso (Burkina-Faso) farming systems, Cah. Agric., 17, 473-478, 2008.

INS: Annuaire statistique des cinquante ans d'indépendance du Niger, available at: http://www.stat-niger.org/statistique/file/ AnnuairesStatistiques/Annuaire_ins_2010/serie_longue.pdf (last access: June 2014), 2010.

Kassie, G. T., Abdulai, A., and Wollny, C.: Implicit Prices of Indigenous Bull Traits in Crop-Livestock Mixed Production Systems of Ethiopia, Afric. Dev. Rev., 22, 842-494, 2010.

Kassie, G. T., Abdulai, A., Wollny, C., Ayalew, W., Dessie, T., Tibbo, M., Hail, A., and Mwai, O.: Implicit prices of indigenous cattle traits in central Ethiopia: Application of revealed and stated preference approaches, ILRI, Nairobi, Kenya, Research Rep. 26, 42 pp., 2011.

Kirmani, A. and Rao, A.: No Pain, No Gain: A critical Review of the Literature on Signaling Product Quality, J. Mark., 64, 66-79, 2000.

Kohler-Rollefson, I.: Indigenous practices of animal genetic resource management and their relevance for the conservation of domestic animal diversity in developing countries, J. Anim. Breed. Genet., 114, 232-238, 1997.

Kugonza, D. R., Nabasirye, M., Hanotte, O., Mpaitrwe, D., and Okeyo, M.: Pastoralists' indigenous selection criteria and other breeding practices of the long-horned Ankole cattle in Uganda, Trop. Anim. Health Prod., 44, 557-565, 2012.

Lancaster, K.: Consumer Demand: a new approach, New-York, Columbia University Press, 176 pp., 1971.

Legendre, P.: Species Associations: The Kendall Coefficient of Concordance Revisited, J. Agric. Biol. Environ. Stat., 10, 226245, 2005.

Makokha, S., Karugia, J., Staal, S., and Oluoch-Kosura, W.: Valuation of cow attributes by conjoint analysis: a case study of Western Kenya, Afr. J. Agric. Resource Econ., 1, 95-113, 2007.

Marichatou, H., Issa, M., Carlo, S., Tiziana, N., Cristofori F., Gabrielle, T., Quaranta, G., and Yenikoye, A.: Insémination artificielle en milieu réel au Niger. Résultats en périurbain de Niamey et à Toukounous (Département de Filingué), Ann. Univ. Niamey., Numéro spécial, 95-102, 2009.

Markemann, A., Zander, K., Siegmund-Schultze, M., Stemmer, A., Roessler, R., Herold, P., Valle Zårate, A.: Towards a sustainable breeding goal for llamas in Bolivia: WTP estimates for selection traits, in: Proceedings of the 9th World Congress on Genetics Applied to livestock Production (WCGALP), Leipzig, Germany, 1-7 August 2010, S.0887, 2010.

Mwacharo, J. M. and Drucker, A. G.: Production Objectives and Management Strategies of Livestock Keepers in South-East Kenya: Implications for a Breeding Programme, Trop. Anim. Health Prod., 37, 635-652, 2005.
Ndumu, D. B., Baumung, R., Wurzinger, M., Drucker, A. G., Okeyo, A. M., Semambo, D., and Sölkner, J.: Performance and fitness traits versus phenotypic appearance in the African Ankole Longhorn cattle: A novel approach to identify selection criteria for indigenous breeds, Livest. Sci., 113, 234-242, 2008.

Ouma, E., Abdulai, A., Drucker, A. G., and Obare, G.: Assessment of farmer preferences for cattle traits in smallholder cattle production systems of Kenya and Ethiopia, Conference on International Agricultural Research for Development, Deutscher Tropentag, Humboldt-University Berlin, Germany, 5-7 October 2004, ID 387, 2004.

Pini, G. and Tarchiani, V.: Les systèmes de production agrosylvo-pastoraux du Niger:3-description et analyse, Politecnico di Torino, Torino, Italia, Working paper 22, 77 pp., 2007.

RGAC: Recensement de l'Agriculture et du cheptel 20052007, résultats définitifs, production animale, répartitions régionales, available at: http://harvestchoice.org/sites/default/files/ downloads/publications/Niger_2005-07_Vol2.pdf (last access: June 2014), 2007

Roosen, J., Fadlaoui, A., and Bertaglia, M.: Economic evaluation for conservation of farm animal genetic resources, J. Anim. Breed. Genet., 122, 217-228, 2005.

Silayoi, P. and Speece, M.: The importance of packing attributes: a conjoint analysis approach, Euro. J. Mark., 14, 1495-1517, 2007.

Tada, O., Muchenie, V., Madzimure, J., and Dzama, K.: Determination of economic weights for breeding traits in indigenous Nguni cattle under in-situ conservation, Livest. Sci., 155, 8-16, 2013.

Tano, K., Kamuanga, M., Faminow, M. D., and Swallon, B.: Using conjoint analysis to estimate farmer's preferences for cattle traits in West Africa, Ecol. Econ., 45, 393-407, 2003.

Vias, F. S. G., Bonfoh, B., Diarra, A., Naferi, A., and Faye, B.: Les élevages laitiers bovins autour de la Communauté Urbaine de Niamey: Caractéristiques, production, commercialisation et qualite du lait [Dairy breeding bovine around Niamey district: characteristics, production, marketing and milk quality], Etud. rech. sahéliennes., 8-9, 159-165, 2003.

Vias, G. and Banzhaf, M.: Etude de l'impact de la hausse des prix du lait et des produits laitiers sur les producteurs et les consommateurs, Etude de cas du Niger, IRAM, Montpellier, 68 pp., 2008.

Wurzinger, M., Ndumu, D., Baumung, R., Drucker, A., Okeyo, A. M., Semambo, D. K., and Solkner, J.: Indigenous selection criteria in Ankole cattle and different production systems in Uganda: 56th Annual Meeting of the European Association for Animal Production (EAAP), Uppsala, Sweden, 5-8 June 2005, L 4.6, 2005.

Wurzinger, M., Ndumu, D., Baumung, R., Drucker, A., Okeyo, A. M., Semambo, D. K., Byamungu, N., and Solkner J.: Comparison of production systems and selection criteria of Ankole cattle by breeders in Burundi, Rwanda, Tanzania and Uganda, Trop. Anim. Health Prod., 38, 571-581, 2006.

Zander, K. K. and Drucker, A. G.: Conserving what's important; using choice model scenarios to value local cattle breeds in East Africa, Ecol. Econ., 68, 34-45, 2008. 